\title{
Design and Deployment of an IoT-Based Air Quality Monitoring System
}

\author{
Tuyen Phong Truong, Duy Thanh Nguyen, and Phong Vu Truong
}

\begin{abstract}
Air quality is getting worse worldwide, especially in cities with high population density and many industrial parks. Raising community awareness and applying science and technology are effective ways to mitigate the negative impacts of industrialization and pollution on the natural environment as well as public health. This work presents the design and deployment of an IoT-based air quality monitoring system, named the Environmental Monitoring System (EnMoS). LoRa (Long-Range) wireless communication technology and innovation sensors being used aim to facilitate the development of data communication network over a large area, improving sensing reliability, extending battery life as well as reducing total system costs. The air quality factors such as particulate matter (PM2.5 and PM10), carbon dioxide $\left(\mathrm{CO}_{2}\right)$, air temperature and humidity, after being read from the sensors were uploaded to a real-time database server for Air Quality Index (AQI) calculation. In addition, for indicating conveniently obtained AQI values a web page is also developed to provide an interactive map along with corresponding charts. A case study on an actual LoRa network consisting of three sensing nodes and a gateway were conducted for validating the feasibility of the system.
\end{abstract}

Index Terms-Air quality monitoring, EnMoS, internet of things, LoRa technology.

\section{INTRODUCTION}

Climate change has been causing significant impacts on people's living conditions, stability, and socio-economic development status in the Lower Mekong River Basin day by day. Besides, due to population growth, the rapid increase of industrialization, as well as indiscriminate use of chemical fertilizers and pesticides in agriculture, are causing serious impacts on the environment, climate, and public health. Air quality is getting worse noticeably, especially in urban areas where high population density and many industrial parks. World Health Organization (WHO) announced that there are approximately 4.2 million premature deaths globally are linked to ambient air pollution [1]. Air Quality Index is a metric to assess how polluted the air is. Recently, air pollution levels in Hanoi and Ho Chi Minh City have reached alarming levels [2]. According to Vietnam's AQI ranking (see Table I), the index reaches a threshold of over 150

Manuscript received June 17, 2020; revised February 5, 2021. This work was supported in part by the Can Tho University, Vietnam, and the Undergrad Research Initiative (URI) Research Symposium, BUILD-IT project.

Tuyen Phong Truong, Duy Thanh Nguyen, and Phong Vu Truong are with the Department of Electronics and Telecommunication Engineering, College of Engineering Technology, Can Tho University, Can Tho, 900000, Vietnam (e-mail: tptuyen@ctu.edu.vn, duyb1609696@student.ctu.edu.vn, phongb1609733@student.ctu.edu.vn). indicating that air quality is harmful to health. In order to mitigate the negative impacts of industrialization and pollution on both the environment and public health, growing community consciousness and applying science and technology is one of the sustainable solutions.

Many environmental monitoring applications based on the Internet of Things (IoT) have been applied successfully in many countries. These projects were employed short-range communications, for example, Zigbee, Wi-Fi, for implementing real-time air quality, both indoor and outdoor, monitoring systems [3]-[7]. With the rapid development of integrated electronic devices and communication technologies (such as low power long-distance wireless communication technology) which allows deploying the distributed sensing systems on a wide-area and reducing maintenance costs as well [8]. Consequently, the objective of this research is to develop large-scale environmental monitoring by adopting IoT-based systems with the advantages of long-distance wireless communication and innovative sensor technology.

A lot of research on air quality has been conducted to reflect the current state of air quality in Vietnam. The scientists used high-resolution satellite images in combination with ground-based meters to calibrate the values in order to observe a large area [9]. The research also focuses on analyzing the factors that affect air pollution and their harm to public health, particularly vulnerable groups due to environmental change [10], [11]. Apart from monitoring AQI values recognized by governments, the research directions seek to identify areas with a high risk of air pollution or other pollutant compounds [12], [13]. Nevertheless, most of the researchers worked on the existing data collection systems instead of developing air quality index monitoring systems themselves.

In Vietnam, most air quality monitoring systems were located in major cities with a high cost of implementation and operation [14]. For example, until now only Hanoi has an automatic air quality monitoring system managed by the Vietnamese government [15], [16]. The implementation of air quality monitoring systems is essential for areas that are at high risk of air pollution, directly affecting human health such as industrial parks, production complexes, university laboratory complexes, and so on. The goal of this study is to design and implement an affordable air quality monitoring systems in areas with several kilometers radius. The monitoring AQI values are reported on a public website for the purposes of early warning and preventive action.

In Fig. 1, on the right, it is a LoRa star network consisting of a gateway and three sensing nodes. LoRa SX1276 modules manufactured by Modtronix were used in order to 
establish wireless links for data transmission [17], [18]. In this network, sensing values of nodes from connected sensors and then sends them to the gateway a role of collecting data from sensing. The gateway then uploads obtained data to a cloud server through an Internet connection, for example, Wi-Fi or $3 \mathrm{G} / 4 \mathrm{G}$.

As can be seen in Fig. 1, administrators can manage the entire system while end users can approach easily via web services from their various devices such as smartphones, tablets, laptops, and personal computers. For sake of convenience and intuition, we refer to develop a web page for a real-time AQI visual map because it can be accessed from any web browser running on many hardware platforms and operating systems.
The remainder of this paper is organized as follows: after stating various causes, effects, and solutions to air pollution and summarizing the related works in Section I, Section II describes the hardware architecture of the EnMoS system. The system utilizes innovative sensor technologies and Semtech's LoRa to deploy a low-power wide-area wireless network for real-time air quality monitoring. Software programming to manage the LoRa network and also to develop a user interactive web page presents in Section III. In Section IV, experiments were carried out on an actual system for monitoring air quality parameters at three typical laboratories on campus of Can Tho University. Finally, Section $\mathrm{V}$ concludes this paper before discussing future works.

TABLE I: THE RANGES AND MEANINGS OF EACH AIR QUALITY INDEX LEVEL AS DEFINED BY VIETNAM'S AQI [19]

\begin{tabular}{|c|c|c|c|}
\hline AQI value & Level of health concern & Meaning & Color \\
\hline $0-50$ & Good & $\begin{array}{l}\text { Air quality is considered satisfactory, and air pollution poses little or no } \\
\text { risk. }\end{array}$ & Green \\
\hline $51-100$ & Moderate & $\begin{array}{l}\text { Air quality is acceptable; however, for some pollutants, there may be a } \\
\text { moderate health concern. }\end{array}$ & Yellow \\
\hline $101-150$ & $\begin{array}{l}\text { Unhealthy for sensitive } \\
\text { groups }\end{array}$ & $\begin{array}{l}\text { Members of sensitive groups may experience health effects. The general } \\
\text { public is not likely to be affected. }\end{array}$ & Orange \\
\hline $151-200$ & Unhealthy & $\begin{array}{l}\text { Everyone may begin to experience health effects; members of sensitive } \\
\text { groups may experience more serious health effects. }\end{array}$ & Red \\
\hline 201-300 & Very unhealthy & $\begin{array}{l}\text { Heal warning of emergency conditions. The entire pollution is more likely } \\
\text { to be affected. }\end{array}$ & Purple \\
\hline $301-500$ & Hazardous & Health alert: everyone may experience more serious health effects. & Brown \\
\hline
\end{tabular}

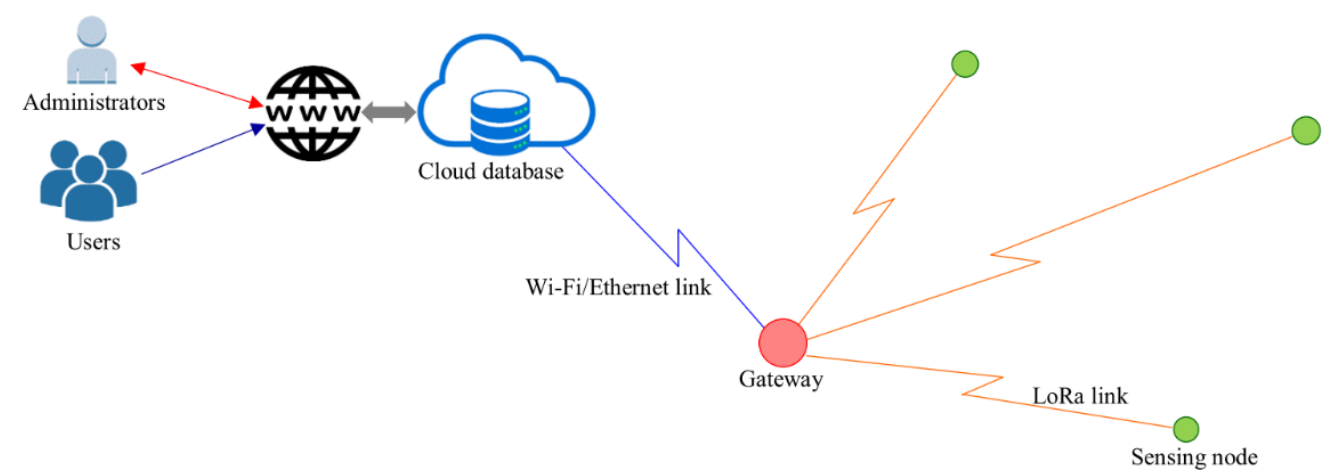

Fig. 1. The architecture of the EnMoS system.

\section{HARDWARE ARCHITECTURE}

\section{A. Hardware System Overview}

The objective of the LoRa wireless sensor network is to establish radio links between the gateway and the sensing nodes for gathering air quality factors. For the sake of simplicity and costs, we use either Raspberry Pi Zero W with Wi-Fi or Raspberry Pi Zero for control boards at a gateway and sensing nodes respectively. We designed and implemented a printed circuit board stacked on both control boards. It helps to wire a radio transceiver and sensors up to the control board for reducing attenuation and interference. For radio communication, Modtronix inAir4 module, a compact LoRa transceiver, offers low power consumption and long-distance radio link for sensing applications [18]. Fig. 2 presents the block diagram of the proposed system.

\section{B. Sensor Used}

Utilizing the advances of Micro Electro Mechanical Systems (MEMS), light scattering, non-dispersive infrared (NDIR), and proven sensing principles, we use various state-of-the-art sensors for better measurement of major air pollutants [20]-[23]. They must be appropriate for the application requirements, taking into account quality, responsiveness, reliability, and long service life. The specifics of the list of sensors used can be found in Table II. The sensors used in this work are carefully selected with a view to balancing quality and device costs aimed at calculating the AQI level. Adopting the principle of laser scattering, the SDS011 sensor can sense the particle concentration from 0.3 to $10 \mu \mathrm{m}$ in the air and send these data to the uP using UART protocol [20]. The MH-Z19B sensor based on the non-dispersive infrared principle can detect the existence of carbon dioxide $\left(\mathrm{CO}_{2}\right)$ in the air with good selectivity and transfer this information to the controller in form of PWM signal [21]. The BME280 sensor provides $\mathrm{I}^{2} \mathrm{C}$ digital signal for humidity, pressure, and temperature with fast response, high accuracy, high resolution, and low noise [22]. CJMCU-4541 sensor is a robust analog MEMS sensor with two fully independent sensing elements such as carbon monoxide $(\mathrm{CO})$ and nitrogen dioxide $\left(\mathrm{NO}_{2}\right)$ on a small footprint [23]. 


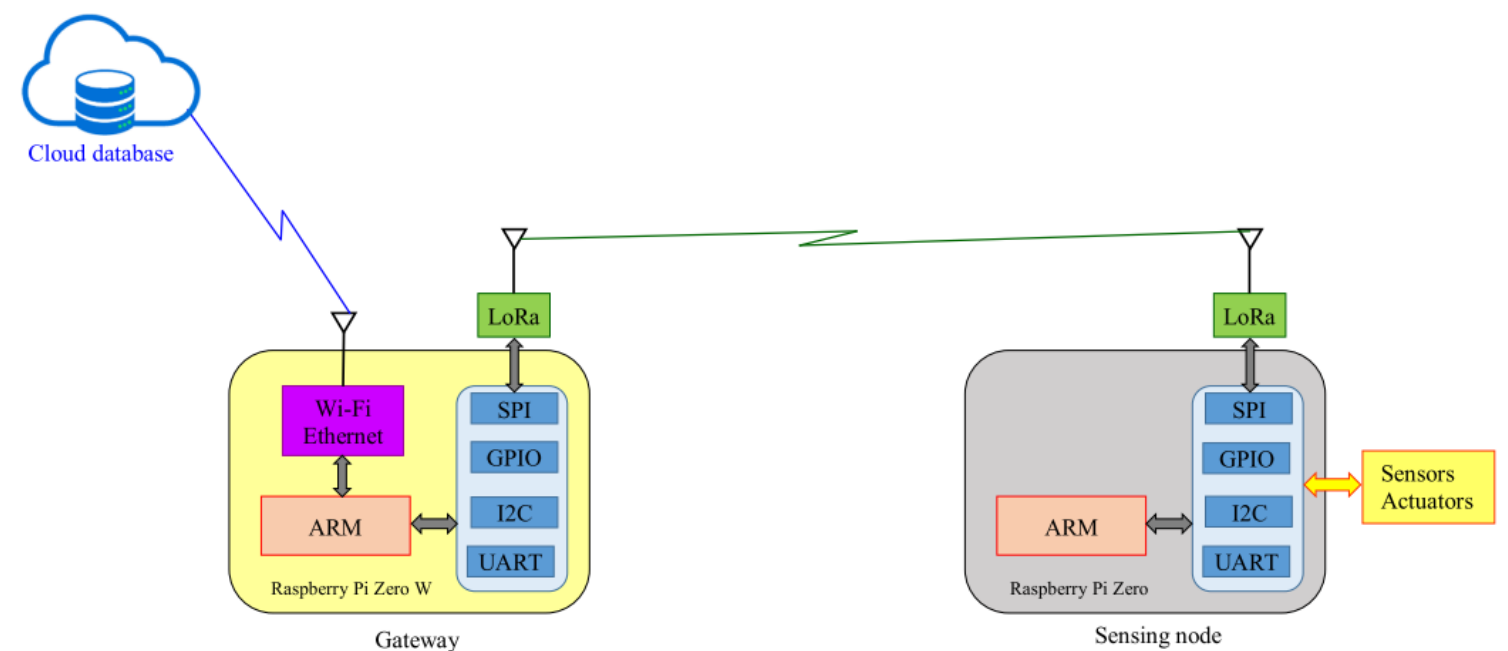

Fig. 2. The block diagram of gateway and sensing nodes: Components and connections.

TABLE II: LIST OF SENSORS USED IN THE ENMOS SYSTEM [20]-[23]

\begin{tabular}{|c|c|c|c|c|c|}
\hline Component & Parameter & Measurement method & Measuring range & Resolution/Sensibility & Accuracy \\
\hline SDS011 & PM2.5, PM10 & Using laser scattering principle. & $0-999 \mu \mathrm{g} / \mathrm{m}^{3}$ & $0.3 \mu \mathrm{g} / \mathrm{m}^{3}$ & $\pm 10 \mu \mathrm{g} / \mathrm{m}^{3}$ \\
\hline MH-Z19 & $\mathrm{CO}_{2}$ & $\begin{array}{l}\text { Using non-dispersive infrared (NDIR) } \\
\text { principle. }\end{array}$ & $0-2000 \mathrm{ppm}$ & - & $\begin{array}{l} \pm 50 \mathrm{ppm}+ \\
5 \% \\
\text { reading } \\
\text { value }\end{array}$ \\
\hline BME280 & $\begin{array}{l}\text { Temperature, } \\
\text { Humidity, and } \\
\text { Pressure }\end{array}$ & $\begin{array}{l}\text { Based on proven sensing principles and } \\
\text { having low power consumption. }\end{array}$ & $\begin{array}{l}-40 \ldots+85^{\circ} \mathrm{C} \\
0 \ldots 100 \% \mathrm{RH} \\
300 \ldots 1100 \mathrm{hPa}\end{array}$ & $\begin{array}{l}0.008 \% \mathrm{RH}, \\
0.18 \mathrm{~Pa}, \\
0.01^{\circ} \mathrm{C}\end{array}$ & $\begin{array}{l} \pm 3 \% \mathrm{RH} \\
\pm 1.0 \mathrm{hPa} \\
\pm 1^{\circ} \mathrm{C}\end{array}$ \\
\hline CJMCU4541 & $\mathrm{CO}, \mathrm{NO}_{2}$ & $\begin{array}{l}\text { Using Micro-Electro-Mechanical Systems } \\
\text { (MEMS) technology. }\end{array}$ & $\begin{array}{l}1 \ldots 1000 \mathrm{ppm}(\mathrm{CO}) \\
0.5 \ldots 10 \mathrm{ppm}\left(\mathrm{NO}_{2}\right)\end{array}$ & $\begin{array}{l}1.2-50(\mathrm{CO}) \\
2\left(\mathrm{NO}_{2}\right)\end{array}$ & - \\
\hline
\end{tabular}

\section{LoRa Transceiver}

Semtech's long-range (LoRa) has been one of the well-known long-range technologies used in large-scale remote sensing systems. It provides accommodation between low data rates and long-distance radio links with different configurations of major parameters: Carrier Frequency $(\mathrm{CF})$, Bandwidth (Bw), Spreading Factor (SF), and Coding Rate (CR). Using the LoRa chip, communication links can reach up to several kilometers in urban areas and tens of kilometers in rural areas [6], [17].

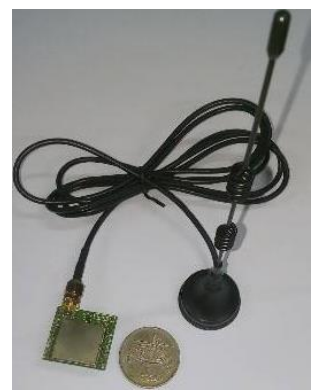

Fig. 3. A LoRa inAir4 module with a 7-dBi antenna.

Modtronix LoRa inAir4 is a compact wireless module that uses a Semtech SX1276 chip with a standard SMA external antenna connector, operating at a frequency from $430 \mathrm{MHz}$ to $435 \mathrm{MHz}$, as shown in Fig. 3. This radio transceiver module can be interfaced with a microprocessor or a microcontroller via the SPI bus. All parameters of the chip are configured conveniently in the program for efficient operation [17].

\section{Hardware Design and Implementation}

An adaptor Printed Circuit Board (PCB) is designed to connect electrical or electronic devices using conductive tracks in order to improve the stability of the system as well as reduce interference. LoRa inAir4 module and sensors are soldered onto the PCB to wire them together. The adaptor interfaces with Raspberry Pi via GPIOs header conveniently. A PCB computer-aided-design (CAD) tool is employed to ensure the proper layout of components and validate operations of circuitry. After that, a computer numerical control $(\mathrm{CNC})$ machine prototyping can produce the $\mathrm{PCB}$ quickly, as shown in Fig. 4.

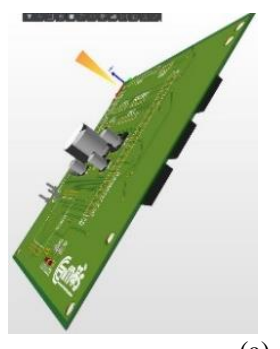

(a)

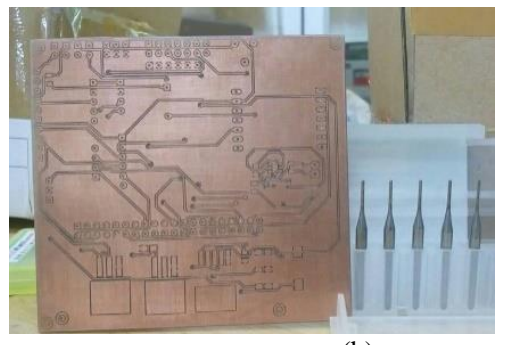

(b)

Fig. 4. (a) 3D PCB Design Presentation (b) PCB of adaptor board.

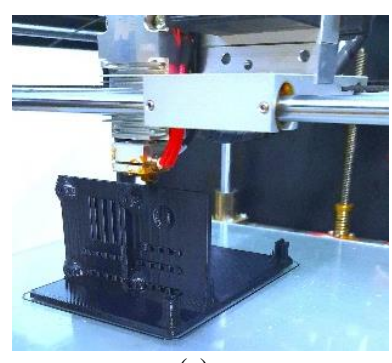

(a)

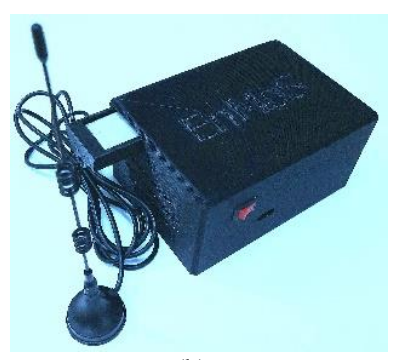

(b)
Fig. 5. (a) 3D printer machine producing a plastic box. (b) A completed box. 


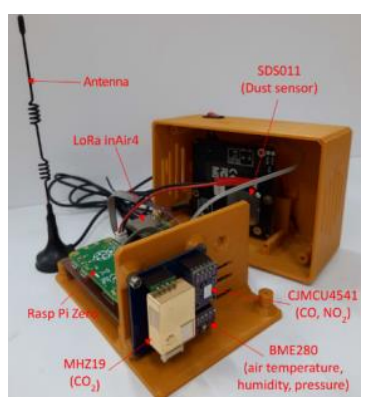

Fig. 6. A photograph of a sensor node: the electronic parts placed in a plastic box to shield them from external effects.

Apart from this, a plastic box was fabricated by a 3D printer machine for protecting electronic components from broken or damage the system. On the front and back of the case, ventilation slots were designed to facilitate the measurement of the air quality sensor. Additionally, as can be seen in Fig. 5, a battery for power supply is also placed inside this box. The complete system of a sensing node is shown in Fig. 6.

\begin{tabular}{|c|c|c|}
\hline No. & Component & Approximate cost (USD) \\
\hline 1 & Raspberry Pi Zero W & $\$ 27.83$ \\
\hline 2 & Modtronix inAir4 LoRa Module & $\$ 12.95$ \\
\hline 3 & Antenna & $\$ 1.33$ \\
\hline 4 & Battery & $\$ 3.86$ \\
\hline 5 & Case & $\$ 3.00$ \\
\hline \multirow[t]{2}{*}{6} & Others & $\$ 5.00$ \\
\hline & Total & $\$ 53.97$ \\
\hline
\end{tabular}

TABLE IV: COST OF THE ELECTRONIC COMPONENTS IN THE SENSING NODE

\begin{tabular}{cll}
\hline \hline No. & Component & Approximate cost (USD) \\
\hline 1 & Raspberry Pi Zero & $\$ 23.55$ \\
2 & Modtronix inAir4 LoRa Module & $\$ 12.95$ \\
3 & Antenna & $\$ 1.33$ \\
4 & SDS011 & $\$ 24.70$ \\
5 & MH-Z19 & $\$ 26.97$ \\
6 & BME280 & $\$ 4.71$ \\
7 & CJMCU4541 & $\$ 24.32$ \\
8 & Battery & $\$ 3.86$ \\
9 & Case & $\$ 3.00$ \\
10 & Others & $\$ 5.00$ \\
& & $\$ 130.39$ \\
\hline \hline
\end{tabular}

Designing and implementing a low-cost system is the objective of this research. The price of a gateway is approximately 54 dollars, while a sensor node is 130.39 dollars, respectively. It is consisting of the costs of raw materials, components, and manufacturing, details can be found in Table III and Table IV.

\section{SOFTWARE DEVELOPMENT}

\section{A. Data Collection}

A LoRa star network is deployed to collect environmental data to a gateway from many sensing nodes distributed in a wide area (see Fig. 1). Sensing data at sensor nodes, with data formation as illustrated in Fig. 7, needs to be sent to the gateway reliably so that a trick scheduling communication must be programmed. The LoRa chip operation has to be controlled by a Python program running on an ARM processor equipped on Raspberry Pi. It is critical to executing interrupt routines to control data exchange within the network effectively. At the gateway, air quality factor values collected from sensing nodes are uploaded to a cloud server either through $\mathrm{Wi}-\mathrm{Fi}$ or the Internet. The obtained data are inserted into a Firebase real-time database and the calculation are executed for AQI values. Fig. 7 depicts the payload structure of a LoRa frame for gathering data in the EnMoS system. The sensors record parameters of air quality and send them to the ARM microprocessor for data processing. For instance, Fig. 8 illustrates a flow chart of the routine in Python programming language for reading and then calculating PM2.5 and PM10 values. Air Quality Index (AQI) is widely used to communicate the public how polluted the air currently. It is necessary to convert the concentrations of pollutants (such as PM2.5, PM10, etc.) into the AQI scale. The numerical value of AQI can be calculated by equation (1) and a breakpoint table. Further details can be found in [24].

$$
\mathrm{AQI}=\frac{\mathrm{AQI}_{\text {High }}-\mathrm{AQI}_{\text {Low }}}{\mathrm{C}_{\text {High }}-\mathrm{C}_{\text {Low }}} \times\left(\mathrm{C}_{\text {Input }}-\mathrm{C}_{\text {Low }}\right)+\mathrm{AQI}_{\text {Low }}
$$

where

- $\mathrm{C}_{\text {Input }}$ input concentration of pollutant

- $\mathrm{C}_{\mathrm{High}}$ : the concentration breakpoint value that is greater than or equal to $\mathrm{C}_{\text {Input }}$

- $\mathrm{C}_{\text {Low }}$ : the concentration breakpoint value that is less than or equal to $\mathrm{C}_{\text {Input }}$

- $\mathrm{AQI}_{\mathrm{High}}$ : the $\mathrm{AQI}$ value corresponding to $\mathrm{C}_{\text {Input }}$

- $\mathrm{AQI}_{\text {Low }}$ : the $\mathrm{AQI}$ value corresponding to $\mathrm{C}_{\text {Input }}$

\section{B. Web Application}

The web page at address https://enmos-ctu.web.app/ is built in order to provide an interactive map along with the corresponding graphs for air quality parameters. It is convenient for people to access the information from any web browser running on a variety of hardware platforms and operating systems. The level of pollutants in the air, such as PM2.5, PM10, and $\mathrm{CO}_{2}$ are presented on separate graphs to observe easily. For instance, PM2.5 values (in $\mu \mathrm{g} / \mathrm{m}^{3}$ ) measured by the SDS011 sensor were depicted in a graph (see Fig. 9). Such graphs are automatically refreshed whenever the Firebase database is updated in real time. It not only allows governors to observe, analyze, and assess the variation of air pollution level but also raises public awareness about environmental pollution.

\begin{tabular}{|c|c|c|c|c|c|c|c|}
\hline $\begin{array}{c}\text { Id } \\
\text { (1 byte) }\end{array}$ & $\begin{array}{l}\text { From } \\
\text { (1 byte) }\end{array}$ & \multicolumn{2}{|c|}{$\begin{array}{c}\text { To } \\
\text { (1 byte) }\end{array}$} & $\begin{array}{l}\text { Data } \\
7 \text { bytes) }\end{array}$ & & & \\
\hline $\begin{array}{c}\text { Temp } \\
\text { (7 bytes) }\end{array}$ & $\begin{array}{l}\text { Humid } \\
\text { ( } 8 \text { bytes) }\end{array}$ & $\begin{array}{c}\text { Pressure } \\
\text { ( } 9 \text { bytes) }\end{array}$ & $\begin{array}{l}\text { PM2.5 } \\
\text { (9 bytes) }\end{array}$ & $\begin{array}{c}\text { PM10 } \\
\text { (9 } 9 \text { bytes) }\end{array}$ & $\begin{array}{c}\text { CO } \\
\text { (9 bytes) }\end{array}$ & $\begin{array}{c}\mathbf{N O}_{2} \\
\text { (7 bytes) }\end{array}$ & $\begin{array}{c}\mathbf{C O}_{2} \\
\text { (9 bytes) }\end{array}$ \\
\hline
\end{tabular}

Fig. 7. Formation of payload. 


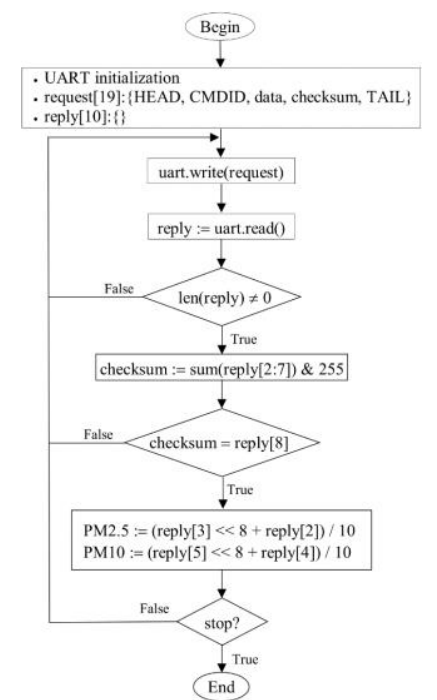

Fig. 8. Flow chart of reading PM2.5 and PM10 data from the SDS011 sensor.

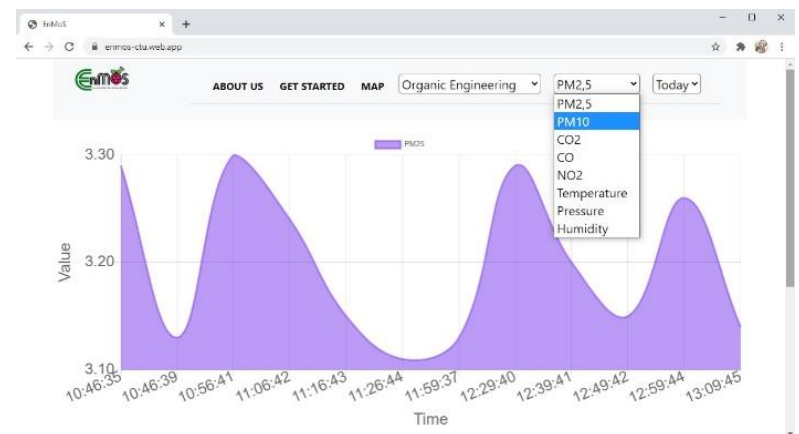

Fig. 9. Web application for real-time air quality parameter monitoring.

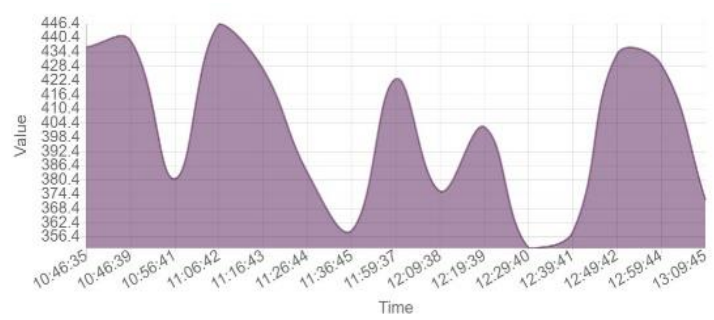

(a)

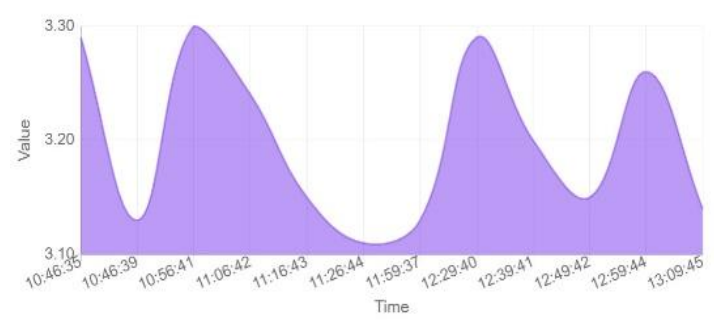

(c)

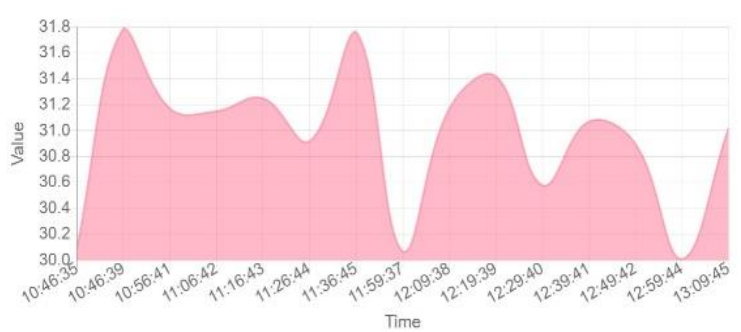

(e)

\section{EXPERIMENTAL RESULTS}

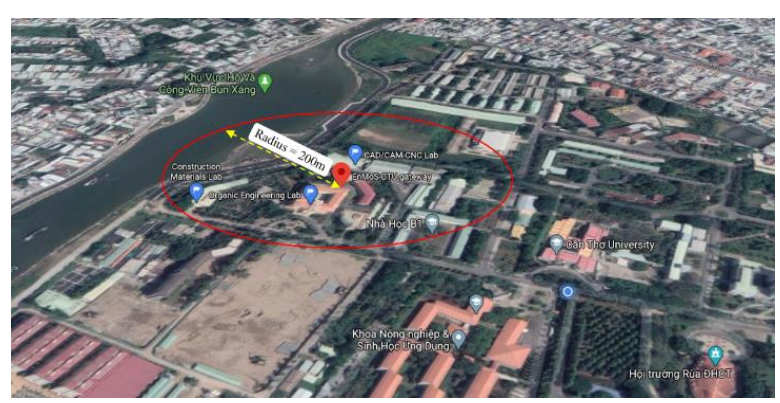

Fig. 10. The positions of three laboratories on the map in the experimental LoRa network.

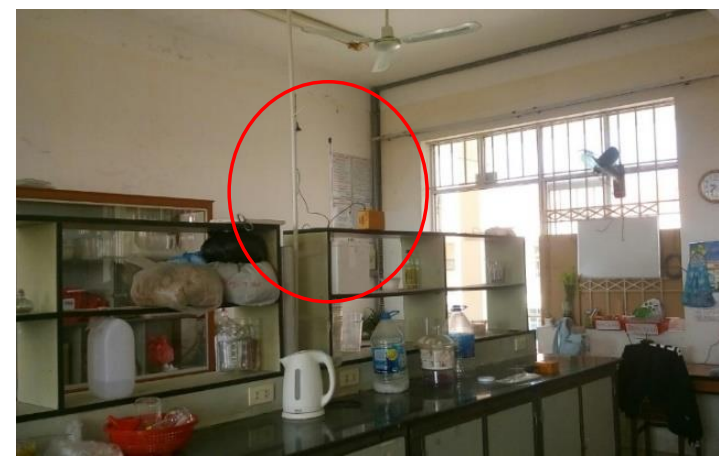

Fig. 11. Sensing node in the organic engineering lab.

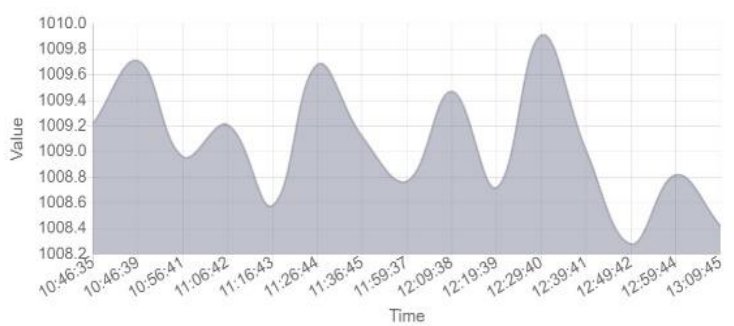

(b)

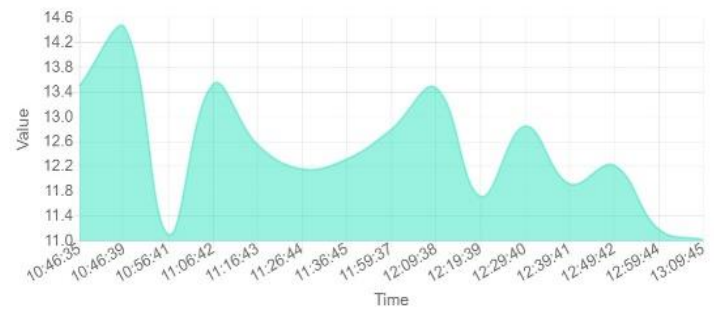

(d)

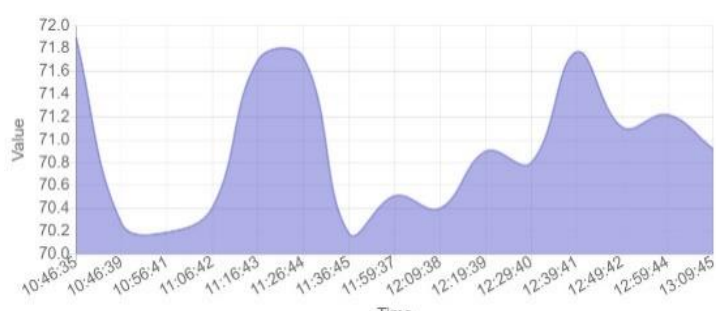

(f)

Fig. 12. Typical graphs showing (a) $\mathrm{CO}_{2}$ (b) air pressure (c) PM2.5 (d) PM10 (e) temperature (f) humidity.

The EnMoS system has been implemented to monitor the air quality of three typical laboratories, Organic Engineering 
Lab, Construction Materials Lab, and CAD/CAM/CNC Lab, on Campus II of Can Tho University (CTU). Fig. 10 depicts the LoRa network deployment, in reality, locations showing on the map with a gateway (red maker) and sensing nodes (blue makers). Although the radius from the gateway to the furthest sensing node is just around 200 meters, the transmission paths were obstructed by various obstacles such as walls, big trees. To overcome this issue, LoRa technology was chosen for data communication within the sensing network. An air quality sensing node was placed at Organic Engineering Lab, as shown in Fig. 11. The gateway was located in the main building of the College of Engineering Technology. During the time, the remote sensing node is in sleep mode to consume as little power as possible. During regular wake-up and transmission 6 times per hour when the gateway requests, it can draw short bursts of current up to $370 \mathrm{~mA}$. Its average power consumption must be managed so that it does not exceed $87 \mathrm{~mA}$. Using two lithium-ion batteries for power supply, each of them has a 2200mAh capacity, which supports its runtime requirement is more than 2 days $(4400 \mathrm{mAh} /(87 \mathrm{~mA} \times 24 \mathrm{~h} / \mathrm{d}) \approx 2.1$ days $)$.

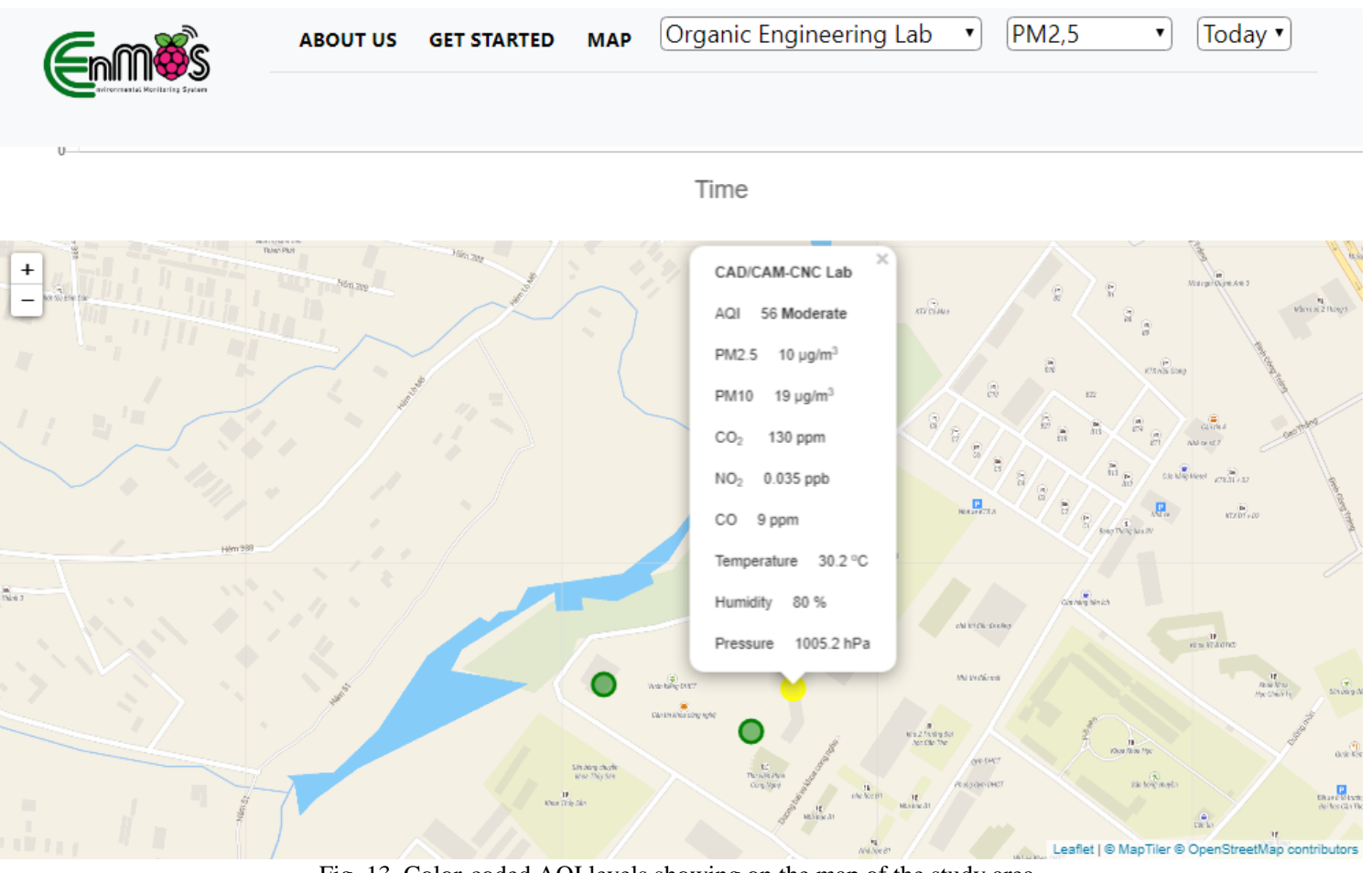

Fig. 13. Color-coded AQI levels showing on the map of the study area.

End users, for example, staff and students, can access the web page from everywhere using PC, smart devices with a web browser to notice the level of air pollution in their workplace. They can switch between the laboratories and then choose a graph to observe the corresponding measured data in real time. Typical graphs displaying $\mathrm{CO}_{2}$, air pressure, PM2.5, PM10, temperature, and humidity are shown in Fig. 12. The air quality of every laboratory is also indicated by color-coded AQI labels on the map (see Fig. 13). According to Vietnam AQI rankings, an AQI level above 100 is considered to be contaminated or unsanitary to humans as can be seen in Table I. For these cases, people should improve air quality by opening the doors and powering on the ventilation system.

\section{CONCLUSION AND FUTURE WORK}

In this paper, we presented the implementation of an IoT-based air quality monitoring system, namely the Environmental Monitoring System (EnMoS) system. The system allows AQI monitoring for a wide area in real time with a visual web map application in light of long-distance wireless technology and cloud database service. We deployed a LoRa star network consisting of a gateway for data collection, then uploading to cloud server and three wireless sensing nodes at three typical laboratories on campus. Each sensing node equips sensors for measuring environmental factors for AQI calculation such as particulate matter (PM2.5 and PM10), $\mathrm{CO}_{2}$, air pressure, temperature, and humidity. Experimental results show that node deployment strategies and methods have a significant impact on the efficiency of air quality sensing. For future work, it is critical to carry the calibration phase with a reference or standard of known and high accuracy for evaluation and validation of the values of all sensors in the proposed system. We also plan to extend the system for air quality monitoring in an area of few tens of square kilometers, for example, all labs on Campus II of Can Tho University. Moreover, based on the positive results of this research, the EnMoS may be applicable for various surveillance applications, for example, saltwater intrusion monitoring, structural health monitoring, and so on.

\section{CONFLICT OF INTEREST}

The authors declare no conflict of interest.

\section{AUTHOR CONTRIBUTIONS}

Tuyen Phong Truong, Duy Thanh Nguyen, and Phong Vu 
Truong carried out system design and testing of the system. All the authors discussed the results, wrote the paper, and contributed to the revision of the paper. All the authors had approved the final version.

\section{REFERENCES}

[1] World Health Organization. (March 2020). Ambient air pollution: Health impacts. [Online]. Available: https://www.who.int/airpollution/ambient/health-impacts/en/

[2] The Saigon Times Daily. (Mar 18, 2019). Hanoi, HCMC among worst $\mathrm{SE}$ Asian cities for air pollution. [Online]. Available: https://english.thesaigontimes.vn/66962/hanoi-hcmc-among-worst-seasian-cities-for-air-pollution.html.

[3] H. T. Nasution, M. A. Muchtar, and A. Simon, "Designing an IoT-based air quality monitoring system," IOP Conf. Ser.: Mater. Sci. Eng, 2019, pp. 1-5.

[4] Y. Y. Wei et al., "A survey of wireless sensor network based air pollution monitoring systems," Sensors, vol. 15, 2015.

[5] C. Toma, A. Alexandru, M. Popa, and A. Zamfiroiu, "IoT solution for smart cities' pollution monitoring and the security challenges," Sensors, vol. 19, 2019.

[6] S. Kaivonen and E. C. H. Ngai, "Real-time air pollution monitoring with sensors on city bus," Digit. Commun. Networks, 2019, vol. 6, pp. 23-30.

[7] H. Gupta et al., "An IoT based air pollution monitoring system for smart cities," in Proc. 1st IEEE Int. Conf. Sustain. Energy Technol. Syst., 2019, p. 173177.

[8] T. P. Truong, B. Pottier, and H. X. Huynh, "Cellular simulation for distributed sensing over complex terrains," Sensors, vol. 18, 2018.

[9] H. N. Nguyen et al., "Mô hình xác định bụi PM10 trong không khí khu vực Hà Nội bằng dữ liệu ảnh vệ tinh Landsat 8 OLI và dữ liệu đo bụi bằng mắt, "VNU J. Sci: Earth and Env. Sci, vol. 34, no. 1, pp. 23-36, 2018.

[10] T. H. Nguyen, N. Tatsuya, and Q. V. Doan, “Air quality modeling study on the controlling factors of fine particulate matter (PM2.5) in Hanoi: A case study in December 2010," Atmosphere, 2020, vol. 11, no. 7, p. 733.

[11] M. T. L. Ly, P. Dung, D. S. Peter et al., "The association between particulate air pollution and respiratory admissions among young children in Hanoi, Vietnam," Sci Total Environ, 2016.

[12] B. Kelly, R. N. Hae, and A. W. Neil, "Analyzing air quality of urban cities in Korea and Vietnam," ACM, 2019, ISBN: 978-1-4503-6186-6.

[13] K. T. Long et al., "Exploratory assessment of outdoor and indoor airborne black carbon in different locations of Hanoi, Vietnam," Sci Total Environ, 2016, vol. 642, pp. 1233-1241.

[14] Northern Environment Observation Center, Vietnam. (2018). Hà Nội cung cấp thông tin trực tuyến về chỉ số quan trắc môi trường tự động. [Online]. Available: http://cem.gov.vn/thong-tin-hoat-dong/ha-noi-cung-cap-thong-tin-truc -tuyen-ve-chi-so-quan-trac-moi-truong-tu-dong

[15] Ministry of Resource and Environment, Vietnam. (2020). Thực trạng và việc công bố thông tin ô nhiễm không khí tại Hà Nội. [Online] Available:

http://www.monre.gov.vn/Pages/thuc-trang-va-viec-cong-bo-thong-ti n-o-nhiem-khong-khi-tai-ha-noi.aspx

[16] Department of Resources and Environment Ho Chi Minh City, Vietnam. (2020). Lắp đặt thêm các trạm đo quan trắc không khí để cảnh báo kịp thời cho người dân. [Online]. Available: http://www.donre.hochiminhcity.gov.vn/tintuc/Lists/Posts/Post.aspx? List=f73cebc3\%2D 9669\%2D400e\%2Db5fd\%2D9e63a89949f0\&ID= 8470

[17] Semtech, Sx1276/77/78/79 -137 MHz to $1020 \mathrm{MHz}$ Low Power Long Range Transceiver. (2016). [Online]. Available: https://www.semtech.com/products/wireless-rf/lora-transceivers/sx12 76

[18] Modtronix. Wireless SX1278 (SX1276) LoRa Module, 433MHz, 3.3V, SMA Connector. [Online]. Available: http://modtronix.com/inair4.html

[19] (2019). Decision No. 1459/QD-TCMT. A guide to calculation and publishing of Vietnam air quality index. [Online]. Available: http://vea.gov.vn/vn/tintuc/tintuchangngay/Documents/QD\%201459 \%20TCMT\%20ngay\%2012.11.2019\%20AQI.pdf

[20] Nova Fitness Co., Ltd. Laser PM2.5 Sensor specification Product model: SDS011 Version: V1.3. [Online]. Available: https://cdn-reichelt.de/documents/datenblatt/X200/SDS011-DATASH EET.pdf.

[21] Zhengzhou Winsen Electronics Technology Co., Ltd. Intelligent Infrared CO2 Module (Model: MH-Z19) User's Manual Version 1.0. [Online]. Available: https://www.winsen-sensor.com.

[22] Bosch Sensortec. BME280 Humidity sensor measuring relative humidity, barometric pressure and ambient temperature. [Online] Available:

https://www.bosch-sensortec.com/products/environmental-sensors/hu midity-sensors-bme280/.

[23] SGX Sensorech. The MiCS-4514 is a compact MOS sensor with two fully independent sensing elements on one package. [Online]. Available:

https://www.sgxsensortech.com/content/uploads/2014/08/0278_Datas heet-MiCS-4514-rev-16.pdf.

[24] H. Yung-Tse, K. W. Lawrence, and K. S. Nazih, Handbook of Environment and Waste Management: Air and Water Pollution Control, Singapore: World Scientific Pub. Co., 2012.

Copyright (C) 2021 by the authors. This is an open access article distributed under the Creative Commons Attribution License which permits unrestricted use, distribution, and reproduction in any medium, provided the original work is properly cited (CC BY 4.0).

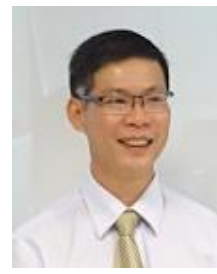

Tuyen Phong Truong received the B.Sc. and M.Sc degrees in electronics engineering from the Can Tho University, in 2002, and from Ho Chi Minh City University of Science, Vietnam, in 2011, respectively; and received the Ph.D. degree in computer science from Université de Bretagne Occidentale, France, in 2018. His research interests include embedded systems, Cyber-Physical Systems (CPS), parallel and distributed algorithms, modeling and simulation of physical phenomena based on cellular automata, long-range communications in wireless sensor networks, especially focusing on LoRa technology.

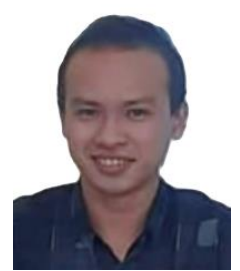

Duy Thanh Nguyen majored in computer engineering, at Can Tho University, Vietnam. He has participated in two phases of the Engineering Projects in Community Service (EPICS), and the Undergrad Research Initiative (URI) Program and received certificate of achievements of Arizona State University (ASU). His studies interests include embedded systems, wireless sensing networks, and 3D modeling.

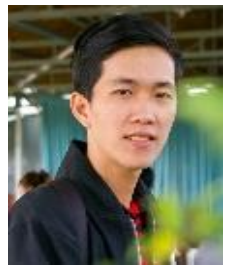

Phong Vu Truong has been a student at Can Tho University since 2016. He received the completion certificate about Safety and Security of Information from Can Tho University Software Center, in 2018. His studies interests include embedded systems, wireless sensor networks and network security. 